\title{
Sociologías de la elección y nociones de libertad: la Renta Básica como proyecto republicano para sociedades de mercado *

\author{
DAVID CASASSAS **
} \\ Universidad de Barcelona
}

RESUMEN. Otorgar un sentido político consciente a los mecanismos y dispositivos en los que toman cuerpo las políticas sociales es algo que exige considerar la descripción de la vida social desde la que éstas, con mayor o menor conciencia de ello, arrancan. La forma en que la filosofía política contemporánea se ha acercado a la propuesta de la Renta Básica constituye un ejemplo especialmente revelador de dicha cuestión. En este texto se presentará, en primer lugar, el marco conceptual y de análisis de la realidad social desde el que la tradición republicana ha abordado las controvertidas nociones de libertad y de neutralidad. En segundo lugar, se cotejará la perspectiva de la libertad republicana con la noción de libertad que opera en el marco del esquema de la libertad real propuesto por Philippe Van Parijs, esquema que se compromete con un criterio de justicia según el cual es justa aquella sociedad en la que el número de opciones disponibles por parte de las personas más desfavorecidas es mayor. En tercer lugar,
ABSTRACT. The making of social policies depends on a particular description of social life. Its specification is something necessary when it comes to give a conscious political direction to all mechanisms and institutional devices that make up social policy as a whole. The way contemporary political philosophy has approached the proposal of a Basic Income constitutes an especially revealing example of this question. In this paper I present, first, the conceptual framework and the analysis of social life from which republican tradition has tackled its controversial notions of freedom and neutrality. Second, I compare the perspective of republican freedom with the notion of freedom that operates within the framework of Philippe Van Parijs' real freedom perspective, which upholds a criterion of justice stating that a free society is that in which the number of options at the most disadvantaged person disposal is the greatest. Third, I defend an approach to Basic Income requiring a categorization of

* Este texto ha sido elaborado en el marco del proyecto de investigación HUM2005-03992/FISO, financiado por el Ministerio de Educación y Ciencia y el FEDER. Algunos de los elementos que aquí aparecen han sido pensados y discutidos de modo embrionario en Casassas y Raventós (2006). Quede constancia de mi gratitud hacia Daniel Raventós por los debates mantenidos a propósito del texto citado y de otros tantos escritos conjuntamente. Asimismo, José A. Noguera ha leído concienzudamente este estudio y ha señalado con generosidad caminos a través de los que ahondar en el trabajo de precisión conceptual que aquí se ensaya. Cualquier error o inexactitud es responsabilidad exclusiva del autor.

** David Casassas ha sido profesor de filosofía de las ciencias morales y sociales en el Departamento de Teoría Sociológica, Filosofía del Derecho y Metodología de las Ciencias Sociales de la Universidad de Barcelona (2001-2005). Actualmente es investigador invitado en la Cátedra Hoover de ética económica y social (UCL, Bélgica). Desde septiembre de 2004 es Secretario de la Basic Income Earth Network (BIEN). 
se planteará la necesidad de una aproximación a la propuesta de la RB que exija una categorización de dichas opciones que priorice aquellas que, aun siendo, quizás, menores, confieran a los individuos mayores garantías de seguridad en la definición y desarrollo de sus planes de vida propios sin interferencias arbitrarias por parte de otros agentes. En esta dirección, se propondrá una aproximación normativa a la propuesta de la Renta Básica que, de acuerdo con la tradición republicana, asuma que aquellas instancias susceptibles de ser consideradas libres $-\mathrm{O}$ no- son, no ya las decisiones en sí mismas, sino los individuos que, encuadrados socio-institucionalmente, han de tomarlas. Finalmente, se señalarán los efectos que el manejo de la perspectiva republicana tiene en el diseño político-institucional de la propuesta de la Renta Básica en el marco de las sociedades de mercado en las que vivimos.

Palabras clave: renta básica, libertad real, Van Parijs.

Otorgar un sentido político consciente a los mecanismos y dispositivos en los que toman cuerpo las políticas sociales es algo que exige considerar la descripción de la vida social desde la que éstas, con mayor o menor conciencia de ello, arrancan. No es lo mismo definir unas medidas de política social, sean éstas las que sean, desde la asunción de que la vida social es un especio políticamente neutro en el que cierta colección de individuos se limitan a firmar contratos de acuerdo estrictamente con la relación psicológica que media entre tales individuos y los objetos externos a ellos, que hacerlo desde el presupuesto de que la vida social se halla henchida de todo tipo de relaciones de poder que definen estatus sociales distintos que, a su vez, arrastran consigo márgenes de elección bien disímiles. options so as to give priority to those options that, even being - maybe - of less importance in numerical terms, confer individuals greater guarantee of security in the definition and development of their own life plans, that is, that ensure the absence of arbitrary interference by others. In that way, I propose, in keeping with the republican tradition, a normative approach to Basic Income in which it is assumed that those entities that are to be considered free - or unfree- are not decisions themselves, but socio-institutionally embodied individuals facing the task of making them. I finally show the outcome of the bringing into play of the republican perspective when it comes to politically -institutionally - design the implementation of Basic Income in the context of the market societies we are living in.

Keywords: basic income, real freedom, Van Parijs.

La forma en que la filosofía política contemporánea se ha acercado a la propuesta de la Renta Básica (RB, en lo sucesivo) constituye un ejemplo especialmente revelador de esta cuestión. En este texto se presentará, en primer lugar, el marco conceptual y de análisis de la realidad social desde el que la tradición republicana ha abordado las controvertidas nociones de libertad y de neutralidad. En segundo lugar, se cotejará la perspectiva de la libertad republicana con la noción de libertad que opera en el marco del esquema de la libertad real propuesto por Philippe Van Parijs, esquema esencialmente cuantitativo en la medida en que el criterio de justicia con el que se compromete es el que establece que son justas aquellas sociedades en las que el número de opciones disponibles por parte de las personas más 
desfavorecidas es mayor. En este punto, se tratará de evaluar las implicaciones del manejo de una noción de libertad desgajada de una sociología debidamente explicitada que la incardine en un programa ético-político de relevancia en términos político-prácticos. En tercer lugar, se planteará la necesidad de una aproximación a la propuesta de la RB que exija una categorización de las opciones de las que los individuos puedan disponer, categorización que priorice aquellas que, aun siendo, quizás, menores, confieran a los individuos mayores garantías de seguridad en la definición y desarrollo de sus planes de vida propios sin interferencias arbitrarias por parte de otros agentes. En esta dirección, se propondrá una aproximación normativa a la propuesta de la RB que, de acuerdo con la tradición republicana, asuma que aquellas instancias susceptibles de ser consideradas libres $\longrightarrow$ no- son, no ya las decisiones en sí mismas, sino los individuos que, encuadrados socio-institucionalmente, han de tomarlas. Finalmente, se señalarán los efectos que el manejo de la perspectiva republicana tiene en el diseño político-institucional de la propuesta de la $\mathrm{RB}$ en el marco de las sociedades de mercado en las que vivimos.

Conviene destacar, pues, de entrada, que la noción de libertad que la tradición republicana, en el mundo moderno como en el mundo antiguo, ha barajado en todo momento puede llegar a ser harto distinta de aquellas que, contemporáneamente, han sido enarboladas por oposición al carácter meramente formal de los ordenamientos jurídico-políticos que el mundo liberal, aupado por la extensión de los códigos civiles napoleónicos, fue consolidando. Recientemente, filósofos como Philippe Van Parijs (1995) han puesto de manifiesto la necesidad de alumbrar esquemas ético-políticos que superen las debilidades de los viejos cuerpos jurídicos de cuño liberal-doctrinario que, comprometidos exclusivamente con la causa de la garantía de la isonomía, de la igualdad ante la ley, se habían desentendido de la suerte de los individuos en el mundo gobernado por dicha ley.

Según los planteamientos de Van Parijs, una sociedad justa en términos estrictamente formales es aquella en la que las instituciones políticas se limitan a garantizar cierto nivel de seguridad y de autopropiedad $^{1}$. Ésta es la razón por la que Van Parijs subraya la importancia de considerar una idea de «libertad real» que incluya un tercer elemento constitutivo: el de la oportunidad. No podemos decir, por ejemplo, que un individuo es realmente libre cuanto acepta un trabajo nocivo y mal pagado porque carece de cualquier tipo de alternativa, esto es, porque carece de la oportunidad de pensar en nuevas y más provechosas opciones. Así, mientras que la libertad formal radica pura y simplemente en la ausencia de constricciones, la libertad real se define como la oportunidad de hacer $X$, cuando el deseo de hacer $X$ implica la posibilidad real de hacer $X$. De este modo, puede decirse que la libertad formal es condicional, en el sentido de que necesita ciertas condiciones de funcionamiento -recursos, muy especialmente- para que pueda, en el mundo real, devenir libertad real. ¿Se encuentra un trabajador asalariado, bajo el capitalismo, forzado a vender su fuerza de trabajo? ¿Goza de la libertad real para no hacerlo?

Sin embargo, la obra de autores como el citado Van Parijs muestra, como se decía, hasta qué punto las asunciones desde las que arrancan ciertos constructos nacidos de la conciencia de los límites de la opción liberal-doctrinaria, pero vinculados también a una sociología cuanto menos borrosa, pueden conducir a postulados bien lejanos de los que la tradición republicana ha hecho propios. Veámoslo, pues, con cierto detenimiento, no sin antes ensayar un dibujo lo más nítido posible del perfil del esquema normativo republicano. 


\section{Significado y alcance de la neutralidad republicana}

La perspectiva republicana muestra un compromiso profundo con la promoción de la independencia socioeconómica de los individuos como condición necesaria para que éstos se hallen habilitados para llevar a cabo los planes de vida propios sin que exista la mera posibilidad de que aquellos que gozan de ciertos privilegios o prerrogativas interfieran en ello. En el marco conceptual y de análisis de la tradición republicana, la vida social se divide en dos esferas que, a su vez, dan lugar a distintas suertes de interdependencias institucionales: la esfera privada, por un lado, que incluye las relaciones de dominación que aparecen en el ámbito productivo y en el reproductivo, esto es, en la empresa o en cualquier centro de trabajo - remunerado, normalmente- y en la familia; $y$, por el otro lado, la esfera pública. Como plantea Domènech (2004), el núcleo de la perspectiva del republicanismo democrático radica en la afirmación de la necesidad de erradicar cualquier forma de dominación que tenga lugar bien en la esfera privada, bien en la esfera pública -o desde la esfera pública hacia la privada-, lo que implica, por lo pronto, una acción político-institucional positiva orientada a deshacer los lazos de dependencia que puedan operar en un lado o en el otro.

La puesta en práctica del ideario republicano exige, pues, atajar no sólo el imperium - las relaciones de dominación procedentes de instancias estatales-, sino también, y muy especialmente, el dominium, esto es, las relaciones de dominación nacidas de vínculos de dependencia que echan sus raíces en el corazón del mundo llamado civil y que, en buena medida, son el origen, también, del imperium. En este sentido, merece la pena subrayar la insuficiencia de ciertas reconstrucciones parciales y poco satisfactorias de la tradición republicana, sesgadas por una lectura romántica de la misma, que, en su exaltación de la esfera pública y de ciertas disposiciones virtuosas de los ciudadanos en ésta encuadrados, han procedido a una confundidora amputación de los atributos de una esfera privada que, de este modo, queda reducida al absurdo de un raquitismo que nunca le correspondió en el seno de la tradición republicana. Se trata, en suma, de reconstrucciones del ideario republicano que han venido a sugerir, a la inversa de lo que en este texto se está planteando, que la esfera pública debe limitarse a prescribir cierto conjunto de disposiciones relativas al buen funcionamiento de las instituciones políticas, por un lado, y, por el otro, a la necesidad de que éstas, en un ejercicio leal y eficaz de sus funciones, eviten a toda costa que su acción invada el espacio que legítimamente corresponde, en exclusividad, a la vida privada, a la llamada, quizás con demasiada precipitación, sociedad civil.

Éste es el caso, por ejemplo, de Hannah Arendt, quien, curiosamente - casi paradójicamente-, tras encendidas proclamas en favor de las disposiciones virtuosas y de la práctica de actividades autotélicas en el espacio público - piénsese, por ejemplo, en ciertos pasajes de La Condición humana, donde se glorifica un ideal de vita activa de difícil manejo-, condenaba cualquier intervención -intromisión, cabría decir en este caso- de las autoridades públicas en el ámbito privado, tomaran estas autoridades la forma que tomaran, sin considerar si la intervención en cuestión podría dotar a los actores sociales de los mecanismos y facultades adecuadas para librarse de los lazos de dependencia civil que los pudieran estar aprisionando $\mathrm{y}$, con ello, otorgarles las herramientas necesarias para poner en práctica los planes de vida propios - entre ellos, quizás, el cultivo, precisamente, de aquellas disposiciones virtuosas y la práctica de aquellas actividades autotélicas en el espacio público-. A los ojos de 
Arendt, tales intervenciones - tales intromisiones - no podían sino conducir a las tierras infaustas donde echan sus raíces los orígenes del totalitarismo. A este respecto, resultan altamente reveladoras las «Reflections on Little Rock», que Arendt (1959) escribe a propósito de las medidas que, en los albores de la época de la defensa de los derechos civiles, se toman con el objetivo de terminar con la segregación racial en las escuelas del Sur de los Estados Unidos. En este texto, tras afirmar que, como judía perseguida por el régimen nazi, asume que todos darán por hecha su simpatía con la causa de los «Negroes», Arendt sostiene que la cuestión en juego no es tanto el bienestar de la población negra por separado, sino la supervivencia de la «República» en su conjunto, por lo menos a largo plazo. $Y$ es que medidas que «politicen» el sistema educativo, el cual, en tanto que parte de la esfera privada, debe quedar al margen de los avatares $\mathrm{e}$ intereses pertenecientes al ámbito de lo público, no pueden sino resultar de lo más nocivo para tal «República», asegura Arendt.

No. La tradición republicana ha andado siempre por otros derroteros. Para el grueso de la tradición republicana, aristocrática o democrática, sólo puede hablarse de sociedad civil cuando se da una asociación de individuos libres e iguales -iguales, en el sentido de igualmente libresen una comunidad en la que todos y cada uno de sus miembros de pleno derecho gozan de independencia material, esto es, de la garantía de un ámbito de existencia social autónoma, lo que, finalmente, permitirá la erradicación de las clases sociales, la erradicación de las distinciones entre rangos. En esta dirección, equiparar, sin miramiento alguno, «vida social» a «sociedad civil» es, en el marco conceptual del republicanismo, un desatino: la vida social puede acoger y acoge todo tipo de formas de dominación que hacen de ella un espacio esencialmente bárbaro ${ }^{2}$.
En efecto, la puesta en práctica del ideario republicano exige no sólo atajar el imperium - las relaciones de dominación procedentes del funcionamiento de las instancias estatales-, sino también, y muy especialmente, erradicar el dominium, esto es, las relaciones de dominación nacidas de vínculos de dependencia propias de la llamada «sociedad civil» y que, en buena medida, son el origen, a su vez, del imperium.

Así, sólo por vía de una intervención mesurada y consentida - disputable, contestable, al decir de Pettit (1999) - por parte de unas autoridades públicas legítimas capaces de poner freno y segar las raíces de la dominación social, podrá extenderse, al conjunto de los individuos llamados a ser miembros de la sociedad civil - de la vida social civilizada- las condiciones materiales necesarias para que ésta aflore. En cambio, la sociedad civil queda partida cuando los recursos materiales que dan acceso a la propiedad - a la independencia material- se hallan repartidos de manera tan desigual que unos cuantos se hallan en condiciones de sesgar pro domo sua el proceso colectivo de toma de decisiones $y$, así, subyugando civilmente a aquellos que deberían ser ciudadanos en condiciones de parigualdad, convertir el orden social en una tiranía oligárquica o plutocrática ${ }^{3}$.

De este modo, sólo cuando se logra sortear estas amenazas a la sociedad civil; sólo cuando es posible disponer una intervención legítima y contestable, por parte de la república, en el ámbito de existencia social autónoma de quienes se hallen en condiciones de erosionar el de los demás; dicho de otro modo, sólo cuando se logra universalizar al conjunto de la comunidad la garantía de la protección y conservación a lo largo del tiempo de este ámbito de existencia social autónoma que legítimamente corresponde a cada individuo; sólo en este momento, puede hablarse de neu- 
tralidad y de tolerancia en un sentido robusto de tales términos.

¿Cómo entiende, pues, el republicanismo la idea de neutralidad? Como se ha visto ya, la tradición republicana, que hace suya una sociología de la dominación que arroja una fotografía de la vida social en la que la presencia del conflicto aparece en todo momento de un modo diáfano; la tradición republicana - digo- postula la necesidad de una intervención estatal orientada a la erradicación de todo tipo de lazos de dependencia entre los individuos, siempre con el objetivo de constituir una sociedad civil efectiva. Pues bien, conviene destacar en este punto que dicha perspectiva abre las puertas a una aproximación materialista a una concepción no paternalista del perfeccionismo moral que llena de contenido sustantivo una idea de neutralidad que, en la tradición liberal, desvinculada de la irreducible dimensión material de la libertad individual, queda, tan a menudo, convertida en una divisa proclamada en el vacío. Pero vayamos paso a paso.

En la línea de lo que hoy plantea Dworkin (1993), el republicanismo siempre ha asumido que los individuos definen algún tipo de reto - un objetivo o un conjunto de objetivos - cuya consecución logra dotar sus vidas de sentido. De este modo, existe la posibilidad de una vida ética, de una vida en la que el carácter el ethos-de los individuos evoluciona, se va conformando, va adquiriendo los atributos que en propiedad le corresponden. Es en este sentido - y sólo en éste- en el que puede afirmarse la presencia, en el seno de la tradición republicana, de un espacio para cierto sentido del perfeccionismo moral: el carácter - la identidadde los individuos no es algo que venga dado ab initio et ante saecula, sino que va desplegándose y adquiriendo un sentido - un significado- a lo largo de sus vidas, como resultado de programas ontogenéticos que se ejecutan —sólo así pueden hacerlo- en el marco de la interacción social.

De ahí la importancia, precisamente, de la garantía política de unos canales socio-institucionales dispuestos para que dicha interacción discurra libremente. De ahí la importancia, en suma, de la garantía política de la posibilidad material - civilde un proceso libre, individual y colectivo, de definición y desarrollo de los planes de vida propios: están en juego ni más ni menos que las identidades personales de los individuos en sociedad.

De este modo, la comunidad en ningún caso define los contenidos - la sustancia- de estos planes de vida. Resulta difícilmente sostenible, pues, el argumento según el cual la tradición republicana ha albergado o alberga ciertas dosis de paternalismo moral y político: pese a haberse afirmado la presencia de unos planes de vida definidos y regidos en un contexto social, no existe ningún tipo de doctrina comprehensiva preexistente o dominante que determine los atributos de dichos planes de vida. Afirmar lo contrario es el resultado, en muchas ocasiones, de confusiones que, en buena medida, se deben a la irrupción, en la academia anglosajona de las décadas de 1980 y de 1990 , de la psicología moral y de la preceptiva política de cuño comunitarista.

¿Qué tarea corresponde, pues, a las instituciones políticas definidas con arreglo a los criterios ético-políticos propios de la tradición republicana? Las instituciones políticas - el Estado-, que tienen como objetivo hacer de la sociedad civil una realidad, deben regular la vida social de manera que se garantice que nadie pueda contar con la mera posibilidad de interferir arbitrariamente en el proceso, pretendidamente libre, de definición y de conducción, por parte de los demás, de los planes de vida propios. Las instituciones políticas el Estado- deben, en definitiva, garantizar la extensión de la libertad republicana como ausencia de dominación. 
En efecto - repito aquí la formulación anterior-, es precisamente porque se aspira al logro de la neutralidad por lo que se exige la garantía política de unos canales socio-institucionales dispuestos para que la interacción de los actores sociales discurra libremente; es precisamente porque se aspira al logro de la neutralidad por lo que se exige la garantía política de la posibilidad material de un proceso libre de definición y desarrollo de los planes de vida propios.

En suma, para constituir una comunidad de individuos republicanamente libres -libres en un sentido que permita, por ejemplo, hablar de la posibilidad de dejar hacer-, es preciso, de antemano, construir políticamente, institucionalmente, las cercas necesarias para que la senda en la que ha de echar a andar - a hacer- el individuo pretendidamente libre no se vea invadida por la maleza de los intereses particulares de aquellas facciones a quienes la herencia o el azar social hayan podido situar en posiciones de privilegio, maleza que pueda llegar a hacer el camino impracticable.

2. Libertad real de la elección $V s$. libertad republicana del sujeto elector: para una categorización de las oportunidades

En el caso de la libertad real, tal y como ésta es definida por Philippe Van Parijs, el marco de análisis es distinto. El esquema normativo vinculado a la idea de la libertad real se articula alrededor de la noción de oportunidad. Así, mientras que en la tradición republicana el hecho de que un individuo no sea realmente libre a la hora de tomar una decisión acerca de la aceptación o no de algún tipo de empleo nocivo, como consecuencia de una ausencia de alternativas u otras oportunidades, es asociado de forma inmediata a un problema de ausencia de la garantía de la existencia material del individuo en cuestión - éste es el elemento central de lo que podría darse en llamar la sociología de la libertad republicana-, la perspectiva de la libertad real no se preocupa por dicha cuestión: bajo el punto de vista de la libertad real, de lo que se trata es de que los individuos tengan a su alcance el mayor número posible de opciones, opciones que se dice que han de ser relevantes, pero respecto a las que no se da un criterio objetivo, empírico e informativo, que permita algún tipo de categorización o de ordenación jerárquica. En otras palabras, pese a declaraciones de principios relativas a la esencial presencia del poder en la misma noción de libertad, sobrevuela el espíritu de una perspectiva que apunta a que no hay opciones a las que se otorgue mayor consideración en el momento de establecer el alcance de la libertad - real- que goza un individuo. El esquema de la libertad real, pues, no establece ningún tipo de conexión entre la libertad - real- y el poder de negociación -o poder de resistencia - Cuanto más alto sea el número de opciones disponibles -y cuanto mayor sea el atractivo de las mismas-, mayor será la libertad real - de los individuos, sean cuales sean - sean como sean - las opciones consideradas. De lo que se trata, pues, es, sencillamente, de señalar que unos ordenamientos jurídicos que se limiten a garantizar la igualdad ante la ley pueden arrojar un mundo en el que los individuos se hallen completamente desprovistos de cualquier tipo de oportunidad. De lo que se trata, pues, es de poner de manifiesto dicha realidad. Y de poner cartas en el asunto, claro está.

De este modo, pese a la presencia de la conocida defensa de una distribución leximin de las oportunidades ${ }^{4}$, la aproximación a la cuestión de la libertad a la que apunta la perspectiva propuesta por Van Parijs es siempre cuantitativa ${ }^{5}$. Esta es la razón por la que el constructo político-normativo de dicho autor se ve ya saciado si existe una acción estatal -a través de la 
garantía de una RB, por ejemplo- que conlleve un ensanchamiento del conjunto de opciones $\mathbf{u}$ oportunidades disponibles, siempre y cuando éste sea suficientemente significativo, por un lado, $y$, por el otro, institucionalmente - técnicamente- estable. Así pues, todo ello se plantea sin que los efectos de una intervención estatal de esta índole sobre la estructura social del mundo en el que tales distribuciones de oportunidades van a tener lugar sean considerados como una variable determinante a la hora de prescribir o no la intervención estatal en cuestión; en otras palabras, todo ello se propone al margen de si dicha intervención estatal garantiza o no la independencia socioeconómica de los individuos.

La idea de libertad propia de la tradición republicana, en cambio, que nace de la preocupación por lograr la consecución de la existencia material de todos los individuos que son considerados ciudadanos plenos, condición necesaria para el ejercicio, precisamente, de su libertad, subraya, lógicamente, la importancia de aquellas opciones cuya disponibilidad pueda conducir a la garantía de la independencia material de los individuos. Por ejemplo, la tradición republicana detecta que ofrecer cierta suma de dinero a un individuo puede proporcionarle cierto número de opciones pero, al mismo tiempo, no garantizar su existencia material - su derecho a la existencia-. Éste puede ser el caso de un artista o de un científico cuyos ingresos dependan de los caprichos de su particular mecenas o patrocinador: el artista y el científico podrán tener un gran número de atractivas opciones a su alcance, pero éstas quedarán sujetas al albur de la mudadiza voluntad de aquel que las proporciona, por lo que se mostrarán inestables $\mathrm{y}, \mathrm{a}$ la postre, inseguras.

También los trabajadores sociales y los gestores de las políticas sociales han sugerido que éste podría ser el caso de aquellas personas que reciben los subsi- dios condicionados propios de los actuales regímenes de bienestar -donde los haya-. Sin duda, percibir - por ejemplo- una pensión no contributiva es algo que incrementa el número de opciones al alcance de su beneficiario, pero en ningún caso pueden desatenderse los vínculos de dependencia que la condicionalidad de dichos subsidios hace aflorar entre sus perceptores y la propia administración pública, del mismo modo que tampoco la presencia de dichos subsidios debe llevar a pensar que de forma automática las asimetrías de poder que originaron la situación de privación que el subsidio pretende corregir hayan desaparecido.

En este sentido, conviene señalar, de acuerdo con los postulados centrales de la tradición republicana, que el hecho de que la RB pueda ser presentada como una medida de política social preferible a los subsidios condicionados propios de los regímenes de bienestar tradicionales no es algo que responda sólo a las ventajas de tipo técnico que por lo común se le atribuyen, sino también $-\mathrm{y}$ sobre todo-, a criterios político-normativos relativos a la mayor seguridad que de aquélla se espera: el funcionamiento de un sistema de RB es menos contingente con respecto a la arbitrariedad de los gestores de los programas de políticas sociales, por lo que el espacio para posibles relaciones de dominación se ve reducido. De este modo, no es un eventual aumento de la cuantía de las prestaciones sociales vinculado a la introducción de la RB, sino la posición social en la que ésta nos sitúa, aquello que hace de dicha medida una opción en materia de política social digna de ser tomada en consideración como contraofensiva - $y$, quizás, alternativa - frente al avance del proceso de desregulación que caracteriza el capitalismo de los últimos lustros.

Así pues, la tradición republicana da prioridad a aquellos factores que garantizan la independencia material de los individuos, en tanto que ésta constituye la 
base de su libertad en el seno de una vida social que, sin intervención alguna, tiende a generar todo tipo de asimetrías de poder. En otras palabras, el republicanismo se compromete con el impulso de aquellas opciones que emanan de $\longrightarrow$ conducen a- un régimen social en el que los individuos son independientes, en el que los individuos gozan de una posición social blindada políticamente que los hace inmunes a cualquier tipo de interferencia arbitraria. De este modo, lejos de perseguir un incremento de las opciones que haga de la toma de decisiones un proceso aparentemente más libre, el republicanismo reivindica la presencia de aquellos mecanismos institucionales que garanticen que tales procesos se podrán llevar a cabo en condiciones de libertad. Al decir de Pettit $(2001,2006)$, y tal y como se verá más adelante, la tradición republicana entiende que la idea de libertad no gira alrededor de elecciones, entendidas éstas en abstracto - la libertad, por tanto, no está choicebased -, sino que apunta a sujetos situados en el trance de llevarlas a cabo - la libertad se halla, bajo este punto de vista, chooser-based-.

Una vez garantizadas, pues, las opciones cardinales - aquellas que hacen posible la independencia material de todos los miembros de la sociedad, que es condición necesaria para la materialización del ideal de reciprocidad en la libertad con la que la tradición republicana se compromete-, las opciones que los individuos puedan gozar posteriormente dejan de ser prioritarias desde el punto de vista moral y político, aun cuando la distribución de tales opciones escupa una sociedad con ciertos -no excesivos- niveles de desigualdad con respecto a los bienes materiales. Dicho de otro modo, una vez que las opciones de las que se deriva la independencia socioeconómica se hallan garantizadas, la disponibilidad o no, por parte de los individuos, de un número mayor o menor de opciones es una cuestión que, si bien puede mantener cierta relevancia en el seno de la tradición republicana, resulta secundaria en términos tanto morales como políticos.

Sea como sea, podría plantearse que, en el corto plazo, la distinción entre libertad real y libertad republicana presenta mayor interés teórico que en términos político-prácticos. Huelga decir que, en el mundo actual, un incremento del número de opciones de los individuos más desfavorecidos significaría, muy probablemente, un incremento también de la libertad republicana de los más dominados.

Más aún. Supongamos que nos hallamos ante dos distribuciones de oportunidades distintas bajo las cuales los individuos cuentan exactamente con los mismos niveles de no-dominación, pero en las que, no obstante, el número de opciones de ciertos individuos para gozar esa igual nodominación en la práctica no es el mismo: en una de estas distribuciones - sociedades-, factores como, por ejemplo, el reparto desigual - pero no desmedidamente desigual, hasta el punto de poner en peligro la ausencia de dominación - de los recursos monetarios podrían conducir a conjuntos de oportunidades disímiles. Pues bien, en este tipo de situaciones, la tradición republicana no dudaría en favorecer las sociedades con mayores oportunidades para algunos.

Sin embargo, es importante resaltar que, al margen de dichas consideraciones, el hecho de que la tradición republicana identifique fuerzas sociales causales que operan en el mundo social real -fuerzas institucionales que la perspectiva de la libertad real desatiende - se convierte en un activo de la mayor importancia tanto teórica como político-práctica en el medio y en el largo plazo.

El quid de la cuestión, pues, radica en el hecho de que el republicanismo detecta con precisión que, aun siendo técnicamente estable una dotación muy elevada de renta que confiera muchas opciones, esta 
dotación puede ser perfectamente censurable si, pese a ofrecer más opciones, nace de dispositivos de política social que no erradican las fuentes de la dominación en la vida social. Ello puede ser así, quizás por tratarse - tal dotación- de una medida parcial: la libertad republicana, a diferencia de la libertad real, tiene en la $\mathrm{RB}$ a una parte del paquete de medidas necesarias, pero no sufícientes, para su cumplimiento. Dicho de otro modo, pese a que es evidente que, en el republicanismo, la RB constituye una medida favorable para la libertad, esta tradición ha caracterizado la libertad de un modo institucional y sociológico tal, que la habilita conceptualmente para detectar posibles situaciones de dominación — de ilibertad-también en un mundo con RB.

En cambio, la perspectiva de la libertad real, que en su definición de libertad apela a las nociones de oportunidad -de opciones disponibles - para superar los límites de la visión formal de la libertad propia del liberalismo doctrinario pero que, como se ha planteado ya, descansa también en una sociología harto imprecisa -si no inexistente: todo ello, como resultado de una opción de carácter metodológico-; la perspectiva de la libertad real - digo - puede establecer que determinados individuos ya son libres porque gozan de una RB, sin tomar en consideración el hecho de que tales individuos se pueden hallar todavía -o no- en una situación de dominación: de hecho, la posible presencia de asimetrías de poder en la vida social es una variable que jamás entró explícitamente en juego en la configuración de esta perspectiva. Y la sociología subyacente a una idea de libertad no puede «darse por hecha»: conviene explicitar con la mayor precisión posible con qué filtros se ha hecho la fotografía de la vida social de la que arranca un esquema normativo que, finalmente, tiene al mundo real en su punto de mira.
Con todo, no es un eventual aumento de la cuantía o una eventual mejora del funcionamiento de las prestaciones sociales vinculado a la introducción de la RB, sino la posición social en la que ésta nos sitúa, aquello que hace de dicha medida una opción en materia de política social digna de ser tomada en consideración como parte de una contraofensiva $-\mathrm{y}$, quizás, alternativa - frente al avance del proceso de desregulación que caracteriza el capitalismo de los últimos lustros.

\section{Libertad del sujeto elector}

y estructura social de la libertad:

la Renta Básica como proyecto republicano para sociedades de mercado

Lo que interesa poner de manifiesto en este punto, pues, es el hecho de que la aproximación que la tradición republicana hace a la cuestión de la libertad parte, precisamente, de una comprensión profunda de esta sociología de la dominación que dicha tradición, de Aristóteles a nuestros días, ha hecho suya. En efecto, el análisis positivo que discurre a lo largo de la obra de los principales exponentes de esta tradición, fuente de la normatividad que va desarrollándose en ella de forma paralela, no persigue otra cosa que la detección de esas fuerzas institucionales que dibujan los contornos del mundo social y que, a partir de ahí, causan las diversas formas de dominación, lleven éstas a interferencias arbitrarias efectivas o no lo hagan -no vale aquí, pues, la hipotética situación de un esclavo favorecido por la generosidad y buen trato de un amo que, del mismo modo que hoy se muestra benevolente con él, mañana puede dispensarle el más indigno de los tratos sin que ello suponga un quebrantamiento de lo estipulado por la ley-.

Con todo, la opción política republicana recoge esta sensibilidad y apunta a la prescripción de unos dispositivos legales e institucionales capaces de deshacer, a tra- 
vés de la garantía de cierta forma de propiedad, los lazos de dependencia que operan en el mundo social; todo ello, en aras de promover una libertad entendida, precisamente, como ausencia de dominación.

Nótese que dicha opción arranca del manejo de una noción de libertad basada, no en una mera descripción a-sociológica de un eventual proceso de toma de decisiones, por parte de individuos aislados, con respecto a cierta colección de objetos - tal descripción arrojaría una noción de libertad estérilmente pura, absoluta-, sino en una caracterización de las diferentes formas de interferencia interpersonal que pueden constreñir tales procesos de decisión en el mundo social y, de ahí, en un criterio empírico y objetivo concerniente al estatus social que ha de gozar el sujeto elector para que con rigor pueda ser considerado libre.

Éste es el sentido en el que, recientemente, Philip Pettit $(2001,2006)$ ha sugerido que no es la «decisión en sí misma» aquella entidad susceptible de merecer -o no-el atributo de «libre», sino «el sujeto que la toma»: la libertad, dice Pettit, debe ser chooser-based, no choice-based. "Los sujetos electores - se pregunta Pettit (2006) - ison libres en la medida en que sus elecciones se toman libremente? $\measuredangle \mathrm{O}$ las elecciones son libres en tanto que son tomadas por sujetos electores libres? En otras palabras ila libertad se basa en la elección o se basa en el sujeto que elige?». Pettit no duda en afirmar, con el grueso de la tradición republicana, que la libertad social no puede entenderse al margen de la consideración de aquellas condiciones materiales que permiten afirmar - $\mathrm{O}$ noque el sujeto que elige se encuentra en condiciones de libertad - como ausencia de dominación-: la afirmación de la libertad social requiere la presencia de marcas, señales institucionalmente trazadas que indiquen que los individuos se hallan protegidos con respecto a la mera posibilidad de interferencias arbitrarias por parte de instancias ajenas. Así, «según la perspectiva de la libertad basada en el sujeto elector, éste será libre en la medida en que tenga garantizada una posición social con respecto a los demás, y sus elecciones serán libres en la medida en que esta posición garantice que aquél quede libre de interferencias en el momento de hacer las elecciones en cuestión; podemos afirmar que haciendo estas elecciones los individuos ejercen o manifiestan su libertad social en tanto que sujetos electores» (Pettit, 2006). En definitiva, sólo en condiciones de independencia material -y civil-, los individuos pueden alcanzar la posición social del freeman harring toniano que, a diferencia del bondsman, puede «vivir por su cuenta» y tomar decisiones basadas en juicios también libres (Casassas y Raventós, 2006).

Cuando tales condiciones se cumplen, no existen razones de principio para que un esquema ético-político de cuño republicano se oponga a los intercambios propios del mercado. En efecto, no existen amena zas particulares a la libertad - como ausencia de dominación- de los individuos que participan en relaciones de intercambio en el mercado cuando, previamente, dicho mercado ha sido políticamente constituido de manera tal que, en su seno, no sean posibles las relaciones de dominación que nacen de $-\mathrm{y}$ conducen a- asimetrías de poder - contractual - y asimetrías informativas, a la imposición de barreras de entrada, a la fijación arbitraria de los precios, etc. ${ }^{6}$. Cabe preguntarse, en este punto, en qué medida la posición de retirada o fallback position que la presencia de una RB conferiría a todos los individuos podría suponer un elemento constitutivo esencial para el diseño de una institución social como un mercado así concebido. En particular, el goce de una RB permitiría poner coto a la «esclavitud a tiempo parcial» 0 «esclavitud salarial» a la que, en palabras de Aristóteles y de Marx, respectivamente, dan pie los contra- 
tos de servicios firmados en ausencia de un sostén material por parte de los trabajadores potencialmente asalariados, quienes no pueden más que «vivir con el permiso» de quienes poseen el control sobre los medios de producción $\mathrm{y}$, con él, el poder de decisión sobre la necesidad de contratarlos o no (Raventós y Casassas, 2004). Así, la garantía de la existencia material $-y$, a la postre, civil- que una RB supone hace de esta medida un dispositivo que puede ser contemplado como fuerza motriz para el cumplimiento de un ideario republicano que halla en «teóricos del mercado" como Adam Smith o el propio Leon Walras referencias destacadas, en un sentido u otro, para su cumplimiento en el mundo contemporáneo.

El mismo Philip Pettit, también en el texto del que se han extraído ya algunas citas (Pettit, 2006), recuerda, muy acertadamente, que «Adam Smith era más fiel [que Rousseau] al republicanismo clásico, e inherentemente más persuasivo, cuando insistía en que, lejos de amenazar la libertad republicana, el mercado podía reducir la dependencia y la dominación [...]. En un mercado de trabajo de funcionamiento apropiado, por ejemplo, nadie dependería ni viviría a merced de ningún dueño: todos podrían cambiar de empleo en caso de encontrarse en el lance de sufrir una interferencia arbitraria». En un régimen republicano, pues - prosigue Pettit-, «[el mercado] respeta la posición de ausencia de dominación con respecto a los demás de la que puedan gozar los individuos, permitiéndoles realizar intercambios sobre una base no coercitiva. Es más, el mercado puede incluso fortalecer dicha posición a través del fomento de su ejercicio y de su reconocimiento».

¿Puede la RB coadyuvar al proceso de constitución política del mercado —de un mercado libre de asimetrías de poder en el que individuos dotados de una inexpugnable posición social se vean habilitados para firmar contratos efectivamente li- bres-, proceso que se ha presentado como condición necesaria para hacer de las sociedades contemporáneas sociedades efectivamente civiles? ¿Puede la RB constituir un elemento esencial para la tarea, esencialmente republicana, de promoción política de una mano invisible que asigne recursos entre individuos cuya capacidad de elegir libremente haya sido dispuesta y blindada institucionalmente? ¿Puede la $\mathrm{RB}$, por lo tanto, convertirse en una pieza indispensable para una acción política dirigida a que esta supuesta mano invisible, lejos de verse eclipsada por el puño visible de los más poderosos contendientes de un auténtico bellum omnium contra omnes, devenga un instrumento para la puesta en funcionamiento de un sistema descentralizado de intercambios realmente libres en todas las esferas de la vida social?

Tal y como ha sido planteado, unida a la sensibilidad moral que inspira el grueso de la tradición en cuestión, la consciencia sociológica con que la tradición republicana ha afrontado su fotografía de la vida social, una fotografía que arroja un mundo henchido de asimetrías de poder, exige la reivindicación de mecanismos institucionales orientados a la conformación política de un régimen de «sujetos electores libres». En este sentido, más allá del importe que pueda alcanzar y del número de opciones que pueda poner al alcance de los individuos, la garantía de una renta de base suficiente para cubrir las necesidades elementales de la vida juega un papel políticamente crucial en la medida $\longrightarrow$ y sólo en la medida - en que sea capaz de detonar un orden social en el que mercados -de trabajo, muy especialmente- - sin asimetrías de poder $y$, por tanto, efectivamente libres permitan una asignación eficaz y apropiadamente flexible de los recursos y de los talentos y, así, se erijan en los cimientos en los que repose una sociedad más eficiente ${ }^{7}$, por un lado, y, por el otro, capaz de satisfacer el requisito de recipro- 
cidad en la libertad con el que la tradición republicana se compromete en última instancia.

\section{REFERENCIAS BIBLIOGRÁFICAS}

ARENDT, H. (1959): «Reflections on Little Rock», Dissent, vol. 6, núm. 1.

CASASSAS, D. (2005): Propiedad y comunidad en el republicanismo comercial de Adam Smith: el espacio de la libertad republicana en los albores de la gran transformación, Barcelona, Universidad de Barcelona.

CAsassas, D., y Raventós, D. (2006): «Property and Republican Freedom: Basic Income as a Right of Existence in Contemporary Societies», en prensa.

DOMÈNECH, A. (2004): El eclipse de la fraternidad. Una revisión republicana de la tradición socialista, Barcelona, Crítica.

DwORKIN, R. (2003): Ética privada e igualitarismo político, Barcelona, Paidós.

Mundó, J. (2005): «Autopropiedad, derechos y libertad (¿debería estar permitido que uno pudiera tratarse a sí mismo como a un esclavo?)», en M. J. BERTOMEU, A. DOMÈnECH y A. DE FrANCISCO (eds.), Republicanismo y democracia, Buenos Aires, Miño y Dávila Editores.

PetTit, P. (1999): Republicanismo. Una teoría sobre la libertad y el gobierno, Barcelona, Paidós.

- (2001): A Theory of Freedom: From the Psychology to the Politics of Agency, Nueva York, Oxford University Press.

- (2006): «Freedom in the Market», Politics, Philosophy and Economics, en prensa.

PINILLA, R. (2001): «¿Es posible una Renta Básica eficiente? Evaluación económica de la Renta Básica», en D. RAveNTós (coord.), La Renta Básica. Por una ciudadanía más libre, más igualitaria y más fraterna, Barcelona, Ariel.

RAVENTÓs, D., y CASASSAS, D. (2004): «La Renta Básica y el poder de negociación de "los que viven con permiso de otros"», Revista Internacional de Sociología, núm. 34.

VAnderborght, Y., y VAN Parius, P. (2005): L'allocation universelle, París, La Découverte.

VAN PARIJS, P. (1995): Real Freedom for All. What (if anything) can justify capitalism?, Oxford, Oxford University Press.
1 Para un estudio detallado acerca de las implicaciones normativas de la asunción de ciertas nociones de autopropiedad en la filosofía política contemporánea, véase Mundó (2005).

2 La retórica de la «civilización»-la politenessopuesta a la «barbarie» que hacen suya varios miembros de la escuela histórica escocesa -entre ellos, sobre todo, Adam Ferguson y, también, Adam Smith- echa sus raíces, precisamente, en una fotografía materialista de la evolución de las sociedades humanas que apunta a la prescripción de dispositivos político-institucionales prontos a arrancar de cuajo las fuentes de las asimetrías de poder que permean el conjunto de la vida en sociedad de los humanos (Casassas, 2005).

\footnotetext{
3 De ahí, por ejemplo, el anhelo de Maquiavelo de poner coto al faccionalismo, anhelo que es recogido, más de dos siglos más tarde, por un Adam Smith que ve aparecer también el peligro de faccionalismo, de vieja y de rueva planta, tardofeudal y protoindustrial, en las posiciones de poder, heredadas o recientemente conquistadas, que se asientan en el seno de la sociedad en transformación que es la Escocia del siglo XVIII.

${ }_{4}$ Van Parijs (1995) denomina ordenamiento leximin de la oportunidad al principio según el cual, en una sociedad libre, la persona que cuente con menos oportunidades no deberá tenerlas menores que aquellas de las que disponga la persona con menos oportu-
} 
nidades dentro de cualquier otro ordenamiento que podamos articular.

${ }_{5}$ Cierto es que el constructo filosófico de Philippe Van Parijs alberga una aproximación sociológicamente consciente, institucional, a la forma en que se obtienen los empleos, así como a los procedimientos, bien poco neoclásicos, a través de los cuales se fijan los salarios. En el esquema de la «libertad real para todos» (Van Parijs, 1995), se asume que «las rentas asociadas a los empleos que ocupamos constituyen el componente preponderante [de la desigualdad en lo que respecta a las dotaciones de las que gozamos a lo largo de nuestra existencia]. Los ocupemos en razón de los talentos que poseamos, de la educación de la que hayamos disfrutado, de la ayuda de parientes o de amigos que nos hayan podido informar o apoyar, de la ciudadanía de la que gocemos, de la generación a la que pertenezcamos o de la localidad en la que residamos, estos empleos constituyen un privilegio. El valor de este privilegio corresponde a la distancia que media entre la remuneración efectiva de un empleo y la remuneración de competencia del mismo empleo que arrojaría una distribución apropiada de las dotaciones» (Vanderborght y Van Parijs, 2005: 65). Este análisis, sin embargo, pese a la agudeza sociológica con la que arrancan los principios criteriales para el establecimiento de la cuantía de la RB, no tiene implicación alguna en punto a determinar la vulnerabilidad social o no de los perceptores de la RB una vez situados en la posición social -de sujeción a algún tipo de dominium o no- que les reserva este mundo con RB: sea cual sea el importe de la RB, ¿sitúa ésta a los individuos a resguardo de cualquier tipo de relación de dominación ejercida sobre su persona? La perspectiva de la libertad real no se halla en condiciones de dar respuesta a tal interrogante.

${ }^{6}$ Conviene recordar, en este sentido, que el proyecto intelectual y político de Leon Walras, activo militante socialista a la par que economista teórico apuntaba a la introducción de todos aquellos dispositivos institucionales necesarios para hacer realidad un escenario social como el definido por su teoria del equilibrio general.

7 Para un análisis de la mejora en la división y especialización del trabajo, así como de los mayores niveles de libertad en la planificación de la actividad productiva de acuerdo con las propias disposiciones, capacitaciones, intereses y vocaciones -energías productivas hasta el momento bloqueadas- que una RB podría hacer posible, véanse Pinilla (2001) y Raventós y Casassas (2004). 